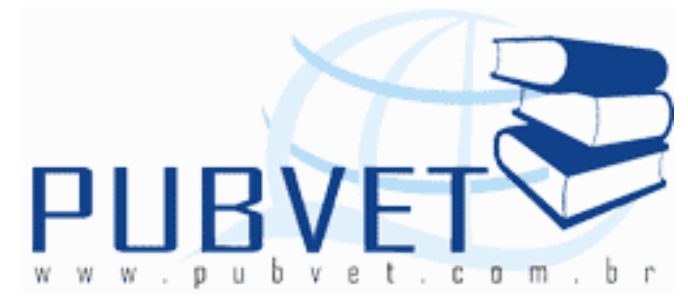

PUBVET, Publicações em Medicina Veterinária e Zootecnia.

\title{
Estresse calórico em vacas leiteiras: implicações e manejo nutricional
}

\section{Diego Lobon Jimenez Filho}

Médico Veterinário, Mestre em Zootecnia pela Universidade de São Paulo, Pirassununga-SP, Brasil. diegojimenez@usp.br

\section{Resumo}

A produção de leite em clima tropical enfrenta algumas adversidades como, por exemplo, o estresse calórico, que influencia negativamente a produção de leite, sendo um dos principais problemas enfrentados pelo setor. Alterações metabólicas, redução na ingestão de alimentos, na produção e teor de gordura no leite, aumento das exigências energéticas para mantença e consumo de água, além de efeitos prejudiciais à reprodução são observadas em vacas durante o estresse calórico. Estratégias como a modificação física do ambiente, melhoramento genético e alterações no plano nutricional são meios de melhorar o bem-estar e a produtividade. O objetivo desta revisão bibliográfica é apresentar os efeitos que o estresse calórico causa em vacas de leite e as possíveis alternativas para o problema.

Palavras-chave: Água, Energia, Produtividade, Proteína, Reprodução. 


\title{
Heat stress in dairy cows: implications and nutritional management
}

\begin{abstract}
Milk production in tropical faced some adversity, for example, heat stress, which negatively influences the production of milk, one of the main problems facing the industry. Metabolic changes, decrease in food intake, production and milk fat content, increased energy requirements for maintenance and water consumption, and adverse effects on reproduction areobserved in cows during heat stress. Strategies such as modifying the physical environment, genetic improvement and changes in nutritional plan are a means of improving the welfare and productivity. The aim of this literature review is to present the effects of heat stress in dairy cows causes and possible alternatives to the problem.
\end{abstract}

Keywords: Energy, Productivity, Protein, Reproduction, Water.

\section{Introdução}

A produção de leite no Brasil tem papel econômico importante, sendo o país classificado como o $5^{\circ}$ maior produtor de leite do mundo, com produção de 30.610 mil toneladas e o $2^{\circ}$ maior rebanho leiteiro composto por 18.200 mil animais (USDA, 2011).

Apesar destes resultados, a produção leiteira nacional vem passando por transformações em razão da adoção de novas tecnologias em busca do crescimento substancial da produtividade. Porém, a maioria dos animais domésticos do mundo são criados em regiões onde estressoressazonais influenciam negativamentea produtividade. Por isso, o fator clima/animal causa perdas expressivas ao setor. Quando os bovinos leiteiros são expostos à temperaturas que não se situam na zona de termoneutralidade tendem a efetuar ajustes metabólicos para manter a homeotermia (COLLIER et al., 1982). O estresse calórico influencia a produção de leite, sendo um dos problemas mais graves nos rebanhos leiteiros nas regiões tropicais. As elevadas temperatura e umidade relativa, assim como a intensa radiação solar, 
JIMENEZ FILHO, D.L. Estresse calórico em vacas leiteiras: implicações e manejo nutricional. PUBVET, Londrina, V. 7, N. 25, Ed. 248, Art. 1640, Suplemento 1, 2013.

são fatores climáticos que causam estresse e estão frequentemente associados ao baixo desempenho do gado leiteiro. Vacas em lactação são particularmente sensíveis ao estresse calórico, devido sua função produtiva específica que requer grande disponibilidade energética e intensa atividade metabólica que conduz à grande produção de calor endógeno (BACCARI JUNIOR, 1989).

\section{Desenvolvimento}

\section{Conforto térmico e zona termoneutra}

Os mínimos custos fisiológicos e a máxima produtividade geralmente ocorrem quando os animais estão na zona de termoneutralidade. A zona termoneutra para bovinos leiteiros situa-se entre 5 e $25^{\circ} \mathrm{C}$ (YOUSELF, 1985; ROENFELDT, 1998) e depende da idade, da espécie, da raça, do consumo alimentar, da aclimatação, do nível de produção, do isolamento externo (pelame) do animal, entre outros (AZEVEDO et al., 2005). Para vacas da raça Holandês, a zona termoneutra está entre 5 e $21^{\circ} \mathrm{C}$, chegando à $24^{\circ} \mathrm{C}$ para vacas Jersey e Pardo- Suíço e, para animais zebuínos $29^{\circ} \mathrm{C}$ (SILVA, 2000).

Armstrong (1994) sugere uma equação para estimar o índice de conforto térmico, desenvolvida por Kelly e Bond (1971), em que é considerada a temperatura ambiente e a umidade relativa do ar e pode ser representada por: ITU = TBs - 0,55 (1-RH) (TBs-58), em que ITU é o índice de temperatura e umidade (adimensional); TBs, a temperatura do ar (graus Fahrenheit); e RH, a umidade relativa do ar expressa em valores decimais. Valores para ITU abaixo de 72 caracterizam um ambiente sem estresse por calor, entre 72 e 78 é caracterizado como estresse brando ou ameno, moderado de 79 a 88 e severo acima de 89.

Aguiar et al., (1996) trabalharam com vacas holandesas e relataram que o ITU brando reduziu a produção destas vacas entre 3,6 e 4,5\%. O valor do índice de temperatura e umidade a partir do qual vacas Holandesas iniciam o declínio na produção de leite é igual a 72 (DAMASCENOet al., 1998; SILVAet al., 2002; AZEVEDO et al., 2005).De acordo com Beede e Collier (1996), a ingestão voluntária de matéria seca é fortemente afetada pela temperatura 
JIMENEZ FILHO, D.L. Estresse calórico em vacas leiteiras: implicações e manejo nutricional.

PUBVET, Londrina, V. 7, N. 25, Ed. 248, Art. 1640, Suplemento 1, 2013.

ambiente e em geral, seu consumo diminui a partir de 25 a $27^{\circ} \mathrm{C}$ de temperatura média diária.

\section{Respostas fisiológicas}

Com a evolução na produção de leite, está associado o aumento da ingestão de matéria seca (MS), elevando-se dessa maneira, o calor metabólico para produção de leite, o qual prejudica o balanço térmico em períodos de estresse calórico. Esses fatores somados a altas temperaturas, alta umidade relativa do ar e radiação solar, provocam estresse calórico nos animais, que se caracteriza por qualquer combinação de condições ambientais que deixem a temperatura ambiente maior que a zona de termoneutralidade do animal (THATCHER, 2010).

As respostas fisiológicas de bovinos frente às variações da temperatura ambiente diferem em razão de fatores como o nível e o estádio de produção, a proporção de volumoso na dieta, a amplitude térmica diária e a umidade relativa do ar (MCDOWELL, 1972). O estresse calórico aumenta as perdas de calor por evaporação e provoca um declínio no metabolismo, visando diminuir a produção endógena de calor. Isso ocorre, pois, os animais possuem quatro vias de perdas de calor conhecidas: radiação, condução, convecção e evaporação, sendo que as três primeiras requerem um gradiente térmico. Porém, à medida que a temperatura ambiente se aproxima da temperatura da pele, a evaporação se torna a principal via de dissipação de calor. Os ruminantes não transpiram tanto quanto humanos ou equinos, sendo assim, a principal via evaporativa é a respiratória, causando taquipnéia e reduzindo a ingestão de alimentos (COLLIER et al., 1981).

O estresse calórico causa alterações no metabolismo de ruminantes, as quais estão associadas a alterações no sistema endócrino. Os hormônios associados com a adaptação ao estresse calórico são antidiurético (ADH), prolactina, do crescimento $(\mathrm{GH})$, tiroxina, glicocorticóides e aldosterona (MCDOWELL, 1985). 
Aumento na transpiração e evaporação pelos pulmões reflete em aumento nos níveis plasmáticos de hormônio antidiurético (EL-NOUTY et al., 1980). O aumento de eletrólitos também está associado a concentrações de aldosterona. O suor de bovinos contém grande quantidade de potássio $(K)$ e baixa quantidade de sódio $(\mathrm{Na})$, por isso, quando grande quantidade de suor é produzida, excretando potássio pela pele, há aumento na excreção renal de sódio, visando o equilíbrio eletrolítico (MCDOWELL, 1985).

Estresse calórico crônico resulta em baixa taxa metabólica, sendo reflexo das baixas concentrações plasmáticas de hormônio do crescimento, tiroxina e glicocorticóides (MITRA et al., 1972; COLLIER et al., 1982).

\section{Ingestão de matéria seca e energia}

O estresse calórico reduz acentuadamente a ingestão de alimentos e por consequência, a produção de leite (NRC, 2001). Holter et al., (1996) relataram, a partir de observações em vacas Jersey, que a ingestão diária de matéria seca começa a reduzir para valores de ITU a partir de 57, sendo que para valores entre 71 e 85 há a máxima redução no consumo, podendo chegar a 22\%. Ainda segundo Holter et al., (1997), vacas holandesas multíparas prenhes, no terço final da lactação diminuem $22 \%$ a ingestão de matéria seca e, primíparas $9 \%$.

Já o NRC (2001), cita queda de até 55\% na ingestão de matéria seca em vacas submetidas a estresse térmico (Fig. 1) e aumentode 7 a $25 \%$ nas exigências energéticas de mantença (Fig. 2), visto que há gasto energético no processo de termólise. MCDOWELL (1985) afirma que bovinos sob pastejo são ser mais afetados que animais em sistema intensivo confinado. Segundo o NRC (1981), quanto maior o teor de forragem na ração, maior é e mais rápido ocorre a redução no consumo de alimento quando os animais estão sob condições estressantes. 


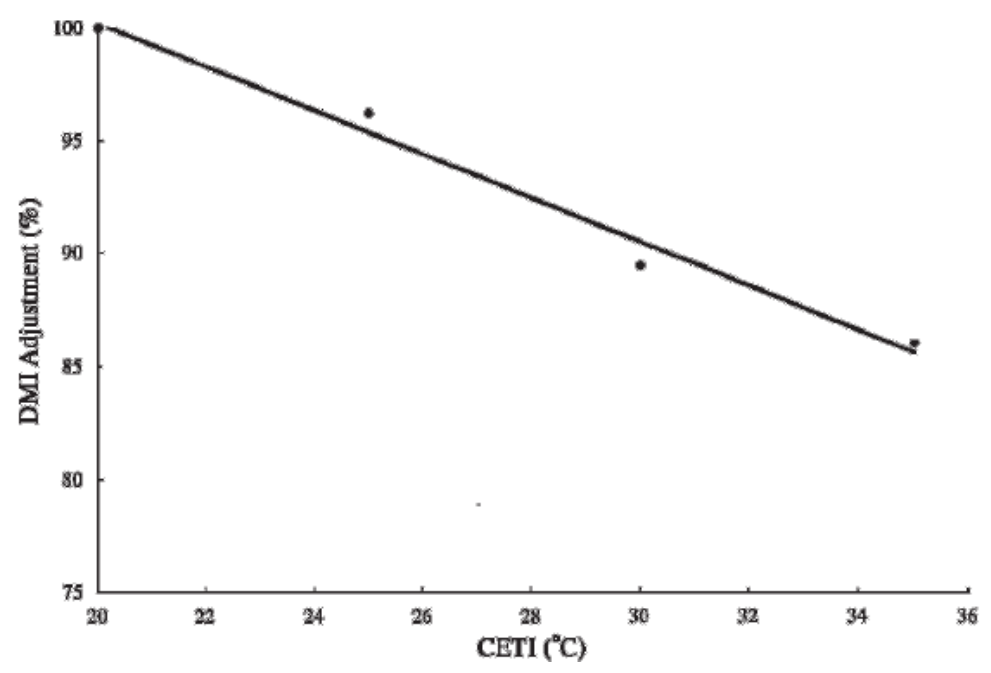

Figura 1 - Efeito de altas temperaturas na Ingestão de Matéria Seca (IMS). CETI = Índice de temperatura efetiva do mês atual. Fonte: Fox e Tylutki (1998).

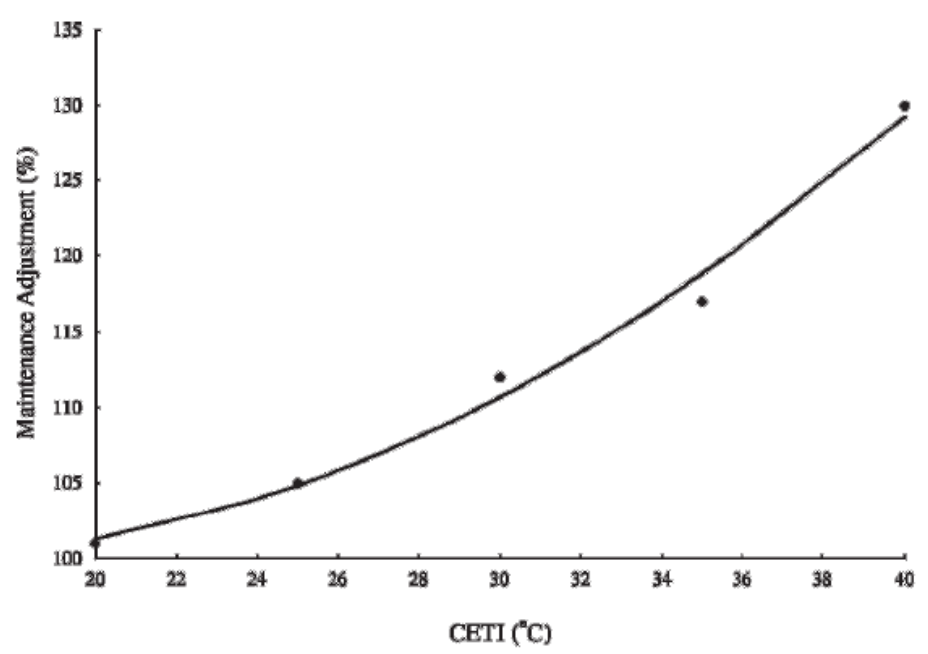

Figura 2 - Efeito do estresse calórico sobre as exigências de mantença. CETI = Índice de temperatura efetiva do mês atual. Fonte: Fox e Tylutki (1998).

O número de contrações ruminais e a taxa de passagem diminuem à medida que a temperatura ambiente se eleva (ATTEBERY e JOHNSON, 1969; WARREN et al., 1974; NRC, 1981). Outro motivo para a redução no consumo pode ser o efeito negativo direto no centro do apetite localizado no hipotálamo (BAILE e FORBENS, 1974). 
A maior parte da energia metabolizável em bovinos sob pastejo é oriunda de ácidos graxos voláteis (AGV) produtos da fermentação ruminal (MCDOWELL, 1985). O estresse calórico reduz a quantidade de AGV produzido no rúmen. A baixa produção aparente de AGV provavelmente está relacionada com a redução do consumo de alimentos (GENGLER et al., 1970). McDowell (1972) também afirma que há redução nas concentrações ruminais de acetato e propionato em bovinos sob estresse calórico.

Para ajuste das exigências de energia líquida metabolizável, se multiplica as exigências de mantença por 1,07 se o animal estiver com taquipnéia superficial ou ainda, por 1,18 se estiver com polipnéia (NRC, 1981).

Fox e Tylutki (1998) criaram uma complexa equação para estimar as exigências de energia para bovinos em condições de estresse calórico:

NEmhs $=1.09857-(0.01343 \times$ CETI $)+\left(0.000457 \times\right.$ CETI $\left.^{2}\right)$

OndeCETI $=27.88-(0.456 \times \mathrm{Tc})+\left(0.010754 \times \mathrm{Tc}^{2}\right)-(0.4905 \times \mathrm{RHC})+$ $\left(0.00088 \times \mathrm{RHC}^{2}\right)+(1.1507 \times \mathrm{WS})-\left(0.126447 \times \mathrm{WS}^{2}\right)+(0.019876 \times \mathrm{TC} \times$ RHC) $-(0.046313 \times$ Tc $\times$ WS $)+(0.4167 \times$ HRS $)$;

NEmhs - Energia líquida metabolizável ajustada para estresse calórico (\%);

Tc - Temperatura media diária atual $\left({ }^{\circ} \mathrm{C}\right)$;

RHC - Umidade relativa média do mês atual (\%);

WS - Velocidade do vento $(\mathrm{m} / \mathrm{s})$;

HRS - Exposição à luz solar direta por dia (h);

Segundo o NRC (2001), devido ao limitado número de trabalhos, não é possível validar a equação de ajuste criada por Fox e Tylutki,(1998), a qual ajusta a ingestão de matéria seca de mantença de acordo com as condições de umidade, temperatura, velocidade do vento e exposição ao sol.

\section{Nutrição proteica}

A qualidade e a forma da proteína oferecida na dieta precisam ser consideradas quando são elaboradas dietas para vacas sob estresse calórico. 
JIMENEZ FILHO, D.L. Estresse calórico em vacas leiteiras: implicações e manejo nutricional. PUBVET, Londrina, V. 7, N. 25, Ed. 248, Art. 1640, Suplemento 1, 2013.

Deficiências de proteína bruta na dieta reduzem sua digestibilidade. Por outro lado, fornecer excesso de proteína bruta aumenta a necessidade energética do animal para a síntese e excreção de uréia.

Linn (1997) sugere que durante o estresse calórico, o nível de proteína degradável no rúmen não ultrapasse $61 \%$ da proteína bruta. Essa indicação baseou-se no fato que o oferecimento de quantidade acima desta recomendada possa ter efeitos deletérios no rúmen, devido à queda de motilidade ruminal e taxa de passagem, promovendo maior permanência da proteína no rúmen, com consequente maior produção de amônia, o que causaria um gasto energético maior ainda para que ela pudesse ser eliminada.

Um estudo feito por Kamal e Johnson (1970), mostra que houve balanço negativo de nitrogênio em bovinos sob estresse calórico agudo, principalmente devido à redução no consumo de ração. Dessa maneira, deve-se ajustar o teor de proteína da ração em função do consumo reduzido, o qual é esperado em situações de estresse calórico (WEST, 1997).

\section{Consumo de água}

A água é sem dúvida um dos nutrientes mais importantes na nutrição de bovinos leiteiros. As exigências de água pelos animais são supridas por: água metabólica, derivada da oxidação tecidual de substratos orgânicos; água contida nos alimentos ingeridos, e; água bebida propriamente dita. A última é significativamente a mais importante via de obtenção de água pelo animal. Água nos alimentos é altamente variável e dependente da fonte de alimento fornecido aos animais.

Segundo o NRC (1981), vários fatores influenciam a ingestão de água em condições de estresse calórico, como: quantidade de alimento ingerido e forma física da dieta; estado fisiológico; raça; qualidade, acesso e temperatura da água.

O consumo de água aumenta em resposta ao estresse calórico, visto que, proporciona conforto ao animal por, exercer imediato resfriamento no rúmen e retículo e servir como principal substrato para termólise evaporativa 
JIMENEZ FILHO, D.L. Estresse calórico em vacas leiteiras: implicações e manejo nutricional. PUBVET, Londrina, V. 7, N. 25, Ed. 248, Art. 1640, Suplemento 1, 2013.

através da sudação e respiração (MCDOWELL, 1985). Entretanto, após o período de aclimatação por várias semanas, o consumo de água pode se estabelecer e se aproximar dos níveis de consumo por animais em termoneutralidade.

McDowell (1972) desenvolveu um estudo com vacas em lactação em câmara climática ( 18 e $30^{\circ} \mathrm{C}$ ), e observou que os animais que foram expostos a temperatura de $30^{\circ} \mathrm{C}$ consumiram $29 \%$ mais água $(57,9$ para 74,7 litros/animal/dia), houve declínio de $33 \%$ no teor de umidade das fezes e aumento de 15, 59 e 50\% na excreção de água via urina, evaporação pela pele e respiração respectivamente. A partir deste estudo, podemos concluir que as exigências de água podem ser de 1,2 a 2 vezes comparados com animais em termoneutralidade.

A qualidade da água também é um quesito de muita importância na produção e saúde de bovinos de leite, seja este em clima tropical ou temperado. Segundo o NRC (2001), características que devem ser considerados para que obtenha êxito no fornecimento de água aos animais são: propriedades organolépticas (odor e sabor), propriedades físico-químicas ( $\mathrm{pH}$, sólidos totais dissolvidos, total de oxigênio dissolvido e dureza), presença de substâncias tóxicas (metais pesados, minerais tóxicos, organofosforados e hidrocarbonetos), presença excessiva de minerais ou compostos (nitrato, sódio, sulfatos e ferro), e presença de bactérias.

Vacas de leite em lactação produziram significativamente, menos leite ingerindo água com alta quantidade de sais, durante os meses de verão, quando comparadas às vacas que ingeriram água normal. Em um estudo feito por Challis et al., (1987) em condições de calor desértico, eles reduziram o teor de sólidos totais dissolvidos de $4.400 \mathrm{mg} / \mathrm{L}$ para $440 \mathrm{mg} / \mathrm{L}$. Com essa redução, houve aumento de $20 \%$ na produção diária de leite, ingestão de água e consumo de alimento.

Devido a importância da água, esta deve estar disponível aos animais em grande quantidade, sendo limpa e fresca e para bovinos em pastejo, é 
JIMENEZ FILHO, D.L. Estresse calórico em vacas leiteiras: implicações e manejo nutricional.

PUBVET, Londrina, V. 7, N. 25, Ed. 248, Art. 1640, Suplemento 1, 2013.

preferível que os bebedouros estejam dispostos perto das áreas de descanso e sombra.

\section{Minerais}

Sabendo da redução de consumo de alimentos durante o estresse calórico, fica evidente que a ingestão de minerais também fique aquém do exigido pelos animais. Alem disso, a sudação realizada pelos animais com objetivo termolítico, proporciona aumento na excreção de potássio (K) pela pele (JOHNSON, 1970). Segundo Beede et al., (1983), a excreção de K chega a ser 5 vezes maior durante o pico de estresse calórico, em comparação a bovinos em condições de termoneutralidade. Jenkinson e Mabon (1973) notaram aumento nas perdas de sódio $(\mathrm{Na})$, magnésio $(\mathrm{Mg})$, cálcio $(\mathrm{Ca})$ e cloro $(\mathrm{Cl})$, porém não de fósforo $(\mathrm{P})$, sendo altamente correlacionado com a taxa de sudação.

Em um trabalho realizado por El-Nouty et al., (1980) com vacas secas e vazias, mostra que os animais sob prolongados períodos a $35^{\circ} \mathrm{C}$, apresentaram níveis $40 \%$ menores de aldosterona plasmática que vacas à $20^{\circ} \mathrm{C}$. Também houve redução sérica e urinária de $\mathrm{K}$, sugerindo a relação da aldosterona com as concentrações urinárias de eletrólitos. Esses eventos fisiológicos são consistentes com a premissa de aumento das exigências de $\mathrm{Na}$ e $\mathrm{K}$ durante o estresse calórico.

Collier et al., (1982), relatam declínio no pH e concentração de eletrólitos, principalmente $\mathrm{Na}$ e $\mathrm{K}$ ruminal, em vacas sob estresse calórico. Isso se deve principalmente ao desequilíbrio na relação ácido-base, promovendo menor excreção salivar de bicarbonato. O desempenho de animais de alta produção por sua vez pode ser mantida com a adição de bicarbonato de sódio na ração, elevando o pH ruminal (SCHNEIDER et al., 1984).

Em temperaturas entre 25 e $30^{\circ} \mathrm{C}$, um adicional de 0,10 gramas de $\mathrm{Na}$ e 0,04 gramas de $\mathrm{K}$ para cada $100 \mathrm{~kg}$ de peso vivo deve ser considerada na formulação das dietas. Entretanto, quando a temperatura ultrapassar os $30^{\circ} \mathrm{C}$, as exigências de mantença de $\mathrm{Na}$ aumentam 0,40 e de $\mathrm{K}$ se elevam 0,36 
$\mathrm{g} / 100 \mathrm{~kg}$ de peso vivo, dessa maneira, totalizando 0,50 gramas de $\mathrm{Na}$ e 0,40 gramas de $\mathrm{K}$ absorvíveis para cada $100 \mathrm{~kg}$ de peso vivo (ARC, 1980).

\section{Vitaminas}

As vitaminas possuem diversas funções no organismo, incluindo funções em vias metabólicas, células envolvidas na imunidade e regulação gênica. A deficiência clínica resulta em doença específica, porém a deficiência subclínica pode levar à queda de produção (NRC, 2001).

Assim como acontece com os minerais, devido à redução no consumo de matéria seca, causado pelo estresse calórico, há concomitante redução no consumo de vitaminas, de modo que sua ingestão possa ficar abaixo das exigências dos animais.

São necessários maiores estudos sobre a interação entre o estresse calórico e a necessidade vitamínica das vacas em lactação, visto que não há muitos estudos sobre este assunto.

\section{Efeitos na produção de leite}

De acordo com Baccari Junior (2001), a homeotermia surge como prioridade no metabolismo do animal, sobrepondo as funções produtivas como, por exemplo, a produção de leite. O estresse calórico pode gerar queda de $17 \%$ a $22 \%$ na produção de vacas de 15 a $40 \mathrm{~kg} /$ dia, respectivamente (PINARELLI, 2003; PORCIONATO et al., 2009).

Além da redução no consumo de alimentos, há aumento do fluxo sanguíneo periférico para reduzir a temperatura corporal, resultando uma redução da absorção de nutrientes e na disponibilidade deles na glândula mamária (MCGUIRE, 1989), e as respostas das vacas em lactação ao estresse térmico incluem, entre outros fatores: redução na produção e na quantidade de gordura no leite (BACCARI JUNIOR, 2001; PORCIONATO et al., 2009).

A recuperação da produção de leite após o estresse calórico ocorre lentamente e em graus que variam com a intensidade e duração do estresse, além da fase da lactação, dentro dos limites fisiológicos da glândula mamária, 
JIMENEZ FILHO, D.L. Estresse calórico em vacas leiteiras: implicações e manejo nutricional.

PUBVET, Londrina, V. 7, N. 25, Ed. 248, Art. 1640, Suplemento 1, 2013.

podendo recuperar totalmente a produção normal ou até comprometer toda a lactação (TITTO, 1998; PORCIONATO et al., 2009).

\section{Efeitos em vacas secas e novilhas}

Também se deve dar atenção às vacas secas gestantes e as novilhas que serão utilizadas na reposição do plantel. Temperaturas altas nos últimos 60 dias pré-parto possuem significante efeito negativo sobre a produção de leite no início e meio da próxima lactação (MOORE et al., 1992; WEST, 2003), sugerindo que vacas secas também sofrem efeitos deletérios.

Quando comparado o peso de bezerros de vacas que tiverem acesso à sombras, com vacas que não tiveram acesso, o primeiro grupo apresentou crias com $3,1 \mathrm{~kg}$ a mais que o segundo grupo, além de uma produção de leite $13,6 \%$ maior (COLLIER et al., 1982). Em trabalho semelhante, vacas que foram resfriadas com aspersores de água e ventiladores durante o período seco produziram crias $2,6 \mathrm{~kg}$ mais pesadas e tiveram um incremento de $3,5 \mathrm{~kg}$ de leite na lactação seguinte (WOLFENSON et al., 1988; WEST, 2003).

As novilhas geram, em relação às vacas, menos calor proveniente de atividades metabólicas, e possuem, em relação à massa corporal e peso das vísceras, uma grande área para troca de calor e, portanto, espera-se que sofram menos com altas temperaturas do que as vacas (WEST, 2003).

\section{Efeitos na reprodução}

A função reprodutiva sofre grande influência do estresse térmico. As vacas apresentam estro variando entre 14 e 18 horas, entretanto, em períodos quentes, nos quais estes animais estão sujeitos ao estresse, o período de estro pode reduzir para 8 a 10 horas, dificultando o diagnóstico de cio e comprometendo o intervalo entre partos, com consequentes perdas produtivas (BARBOSA e DAMASCENO, 2002; CRUZ et al., 2011).

Segundo Hansen (2007), em períodos de estresse calórico os folículos ovarianos tendem a produzirem oócitos de menor capacidade de fertilização e desenvolvimento embrionário anormal.Vacas submetidas à condições de 
JIMENEZ FILHO, D.L. Estresse calórico em vacas leiteiras: implicações e manejo nutricional. PUBVET, Londrina, V. 7, N. 25, Ed. 248, Art. 1640, Suplemento 1, 2013.

estresse calórico, por apresentarem redução no consumo de alimentos, acabam entrando em balanço energético negativo (BEN) mais acentuado. Este fato eleva a utilização de glicose pelas células, diminuindo sua utilização como fonte de energia para manutenção da produção de leite. Contudo, este processo implica sobre a fertilidade, pois o ovócito, o embrião e o feto utilizam a glicose como fonte de energia, e a taxa de clivagem e o desenvolvimento dos blastocistos são reduzidos quando mantidos em ambientes com baixo teor de glicose (CRUZ et al., 2011).

Hansen e Aréchiga (1999) demonstraram que os embriões respondem ao estresse térmico maternal, dependendo do estágio de desenvolvimento e que o período de estresse térmico mais crítico para o embrião é entre o final da maturação oocitária, ovulação e os primeiros dias após a fertilização. Embora os embriões mais jovens sejam mais sensíveis a altas temperaturas, os embriões em estágio avançado também podem apresentar comprometimento no desenvolvimento.

\section{Alternativas}

Segundo Antunes et al., (2009), há três estratégias de manejo que podem ser adotadas minimizando, de forma eficaz, os riscos do estresse calórico:

1) Modificação física do ambiente, através de sistemas de ventilação e sombreamento, que proporcionam redução no estresse calórico, podendo assim aumentar a produção de leite e o bem-estar animal.

2) Desenvolvimento genético de raças mais tolerantes ao calor, através de cruzamentos industriais que proporcionem a expressão de maior resistência frente a condições adversas.

3) Melhoramento nutricional através do oferecimento de uma dieta "fria", ou seja, dietas que possibilitam o fornecimento de nutrientes para a produção de leite, aliado a um menor incremento calórico proveniente da fermentação e metabolismo dos alimentos. Dietas como estas possuem como característica o alto teor de energia oriunda de óleos, 
fibra de alta fermentação, menor degradabilidade de proteínas e alto conteúdo de nutrientes protegidos. Ainda, a suplementação mineral com potássio, sódio e magnésio, além de prover uma água de boa qualidade, são práticas que podem minimizar os efeitos gerados pelo estresse calórico.

\section{Considerações Finais}

Em condições de estresse calórico deve-se tentar promover alterações físicas no ambiente e aumentar a densidade nutricional da ração visando dessa maneira anular os possíveis efeitos ambientais negativos que atuam como agentes deletérios à produção de leite.

O efeito causado pelo estresse calórico no desempenho animal tende a se tornar um viés importante na formulação de dietas, visto que, cada vez mais os animais são criados de forma confinada, além da previsão de aquecimento global, que acaba por influenciar a tudo e todos.

\section{Referências Bibliográficas}

AGRICULTURAL RESEARCH COUNCIL. Nutrients requirements of ruminant livestock. London: Commonwealth agricultural bureaux, 1980, 351p.

AGUIAR, I.S.; BACCARI JÚNIOR, F.; GOTTSHALK, A.F. et al., Produção de leite de vacas Holandesas em função da temperatura do ar e do índice de temperatura e umidade. In: REUNIÃO ANUAL DA SOCIEDADE BRASILEIRA DE ZOOTECNIA, 37., 1996, Fortaleza. Anais... Fortaleza: Sociedade Brasileira de Zootecnia, p.617-619, 1996.

ANTUNES, M.M.; PAZINATO, P.G.; PEREIRA, R.A.; SCHNEIDES, A.; BIANCHI, I.; CORRÊA, M.N. Efeitos do estresse calórico sobre a produção e reprodução do gado leiteiro. NUPEEC: Núcleo de Pesquisa, Ensino e Extensão em Pecuária, Universidade Federal de Pelotas, 2009.

ARMSTRONG, D.V. Heat stress interaction with shade and cooling. Journal of Dairy Science, v.77, p.2044-2050, 1994.

ATTEBERY, J.T.; JOHNSON, H.D. Effects of Environmental Temperature, Controlled Feeding and Fasting on Rumen Motility. Journal of Animal Science. v.29, n.5, p.734-737, 1969.

AZEVEDO, M., PIRES, M. F. A., SATURnino, H. M., et al., Estimativa de níveis críticos superiores do índice de temperatura e umidade para vacas leiteiras 1/2, 3/4 e 7/8 HolandêsZebu em Lactação. Revista Brasileira de Zootecnia, v.34, n.6, p.2000-2008, 2005. 
BACCARI JÚNIOR, F. Manejo ambiental para a produção de leite nos trópicos. In: CICLO INTERNACIONAL DE PALESTRAS SOBRE BIOCLIMATOLOGIA ANIMAL, 1., 1986, Botucatu. Anais... Jaboticabal: FUNEP, 1989. p.45-53.

BACCARI JÚNIOR, F. Manejo ambiental da vaca leiteira em climas quentes. Londrina, 2001.

BAILE, C.C.; FORBES, J.M. Control of feed intake and regulation of energy balance in ruminants. Physiologycal Reviews. v.54, n.1, p.160-213, 1974.

BARBOSA, O.R.; DAMASCENO, J.C. Bioclimatologia e bem estar animal aplicados à bovinocultura de leite. Universidade Estadual de Maringá, Maringá, PR, Junho, 2002.

BEEDE，D.K.; MALLONEE，P.G.; SCHNEIDER，P.L.; WILCOX，C.J.; COLLIER, R.J. Effect of production systems on performance, body composition and lipid and mineral profiles of soft tissue in cattle. Journal of Animal Science. v.57, n.4, p.1020-1028, 1983.

BEED, D. K., COLLIER, R. J., Potencial nutritional strategies for intensively maneged cattle during thermal stress. Journal of Animal Science. v.62, n.3, p.543-555, 1986.

CHALLIS, D.J.; ZEINSTRA, J.S.; ANDERSON, M.J. Some effects of water quality on the performance of high yielding dairy cows in an arid climate. Veterinary Research. v.120, p.12-15, 1987.

COLLIER, R.J.; ELEY, R.M.; SHARMA, A.K.; PEREIRA, R.M.; BUFFINGTON, D.E. Shade management in subtropical environment for milk yield and composition in Holstein and Jersey cows. Journal of Dairy Science. v.64, n.5, p.844-849, 1981.

COLLIER, R. J., DOELGER, S. G., HEAD, H. H.,THATCHER, W. W., WILCOX, C. J. Effects of heat stress during pregnancy on maternal hormone concentrations, calf birth weight and postpartum milk yield of Holstein cows. Journal of Animal Science, v.54, p.309-319, 1982.

COLLIER, R.J.; BEEDE, D.K.; THATCHER, W.W.; ISRAEL, L.A.; WILCOX, C.J. Influences of environment and its modification on dairy animal health and production. Journal of Dairy Science. v.65, n.11, p.2213-2227, 1982.

CRUZ, L.V.; ANGRIMANI, D. S.R.; RUI, B.R.; et al., Efeitos do estresse térmico na produção leiteira: Revisão de Literatura. Revista Científica Eletrônica de Medicina Veterinária. n.16, 2011.

DAMASCENO, J.C.; BACCARI JÚNIOR, F.; TARGA, L.A. Respostas fisiológicas e produtivas de vacas holandesas com acesso à sombra constante ou limitada. Revista Brasileira de Zootecnia, v.27, n.3. p.595-602, 1998.

EL-NOUTY, F.D.; ELBANNA, I.M.; DAVIS, T.P.; JOHNSON, H.D. Aldosterone and ADH response to heat and dehydration in cattle. Journal Applied Physiology: Respiratory Environmental and Exercise Physiolgy. v.48, n.2, p.249-255, 1980.

FOX, D.G.; TYLUTKI, T.P. Accounting for the effects of environment on the nutrient requirements of dairy cattle. Journal of Dairy Science. v.81, n.11, p.3085-3095, 1998.

GENGLER, W.R.; MARTZ, F.A.; JOHNSON, H.D.; KRAUSE, G.F.; HAHN, L. Effect of temperature on food and water intake and rumen fermentation. Journal of Dairy Science. v.53, n.4, p.434-437, 1970. 
HANSEN, P.J.; ARÉCHIGA, C.F. Strategies for managing reproduction in the heat stresseddairy cow. Journal of Animal Science, v.77, p.36-50, 1999.

HANSEN, P. J. Manejo da vaca de leite durante o estresse calórico para aumento da eficiência reprodutiva. In: XI CURSO NOVOS ENFOQUES NA PRODUÇÃO E REPRODUÇÃO DE BOVINOS, 2007. Uberlândia, MG Anais... 2007, p.3-12.

HOLTER, J. B., WEST, J. W., MCGILLIARD, M.L, et al., Predicting ad libitum dry matter intake and yield of Jersey cows. Journal of Dairy Science. v.79, p.912-921, 1996.

HOLTER, J.B.; WEST, J.W.; MCGILLIARD, M.L. Predicting ad libitum dry matter intake and yield of holstein cows. Journal of Dairy Science. v.80, n.9, p.2188-2199, 1997.

JENKINSON, D.M.; MABON, R.M. The effect of temperature and humidity on the skin surface $\mathrm{pH}$ and the ionic composition of skin secretions in Ayrshire cattle. The British Veterinary Journal. v.129, n.3, p.282-295, 1973.

JOHNSON, K.G. Sweating rate and the electrolyte content of skin secretions of Bos taurus and Bos indicus cross-bred cows. The Journal of Agricultural Science. v.75, n.3, p.397-402, 1970.

KAMAL, T.H.; JOHNSON, H.D. Whole body $\mathrm{K}^{40}$ loss as a predictor of heat tolerance in cattle. Journal of Dairy Science. v.53, n.12, p.1734-1738, 1970.

KELLY, C.F.; BOND, T.E. Bioclimatic factors and their measurements. In: NATIONAL ACADEMY OF SCIENCES, (Ed.) A guide to environmental research on animals. Washington: National Academy of Sciences, p.71-92, 1971.

LINN, J.G. Nutricional manegement of lactating dairy cows during periods of heat stress. Dairy Update Issues, University of Minessota. n.125, 1997

MCDOWELL, R.E. Improvement of Livestock Production in Warm Climates. San Francisco. FREEMAN. 1972. 711p.

MCDOWELL, R.E. Nutrition of grazing ruminants in warm climates. Orlando. ACADEMIC PRESS. 1985. 443p.

MCGUIRE, M.A.; et al., Effects of thermal stress and level of feed intake on portal plasma flow and net fluxes of metabolites in lactating cows. Journal of Animal Science, v.67, n.4, p.1050-1060, 1989.

MITRA, R.; CHRISTINSON, G.I.; JOHNSON, H.D. Effect of prolonged thermal exposure on growth hormone $(\mathrm{GH})$ secretion in cattle. Journal of Animal Science. v.34, n.5, p.776-779, 1972.

MOORE, R.B.; FUQUAY, J.W.; DRAPALA, W.J. Effects of late gestation heat stress on postpartum milk production and reproduction in dairy cattle. Journal of Dairy Science, v.75, p.1877-1882, 1992.

NATIONAL RESEARCH COUNCIL. Effect of environment on nutrient requirements of domestic animals. Washington: National Academy Press, 1981, 152p.

NATIONAL RESEARCH COUNCIL. Nutrient requirements of dairy cattle. $7^{a}$ ed. Washington: National Academy Press, 2001, 381p. 
PINARELLI, C. The effect of heat stress on milk yield. Latte, Milan, v.28, n.12, p.36-38, 2003.

PORCIONATO, M.A.F.; FERNANDES, A.M.; NETTO, A.S.; et al., Influence of heat stress on milk yield and quality. Revista Acadêmica de Ciências Agrárias e Ambiental. v.7, n.4, p.483490, 2009.

ROENFELDT, S. You can't afford to ignore heat stress. Dairy Manage, v.35, n.5, p.6-12, 1998.

SCHNEIDER, P.L.; BEEDE, D.K.; WILCOX, C.J.; COLLIER, R.J. Influence of dietary sodium and potassium bicarbonate and total potassium on heat-stressed lactating dairy cows. Journal of Dairy Science. v.67, n.11, p.2546-2553, 1984.

SILVA, I.J.O.; PANDORTH, H.; ACARARO JÚNIOR, E. et al., Efeitos da climatização do curral de espera na produção de leite de vacas Holandesas. Revista Brasileira de Zootecnia, v.31, n.5, p.2036-2042, 2002.

SILVA, R.G. Introdução à bioclimatologia animal. São Paulo: NOBEL. 2000. 286p.

THATCHER, W. W. Manejo de estresse calórico e estratégias para melhorar o desempenho lactacional e reprodutivos em vacas de leite. XIV CURSO NOVOS ENFOQUES NA PRODUÇÃO E REPRODUÇÃO DE BOVINOS, 2010. Uberlândia, MG. Anais... 2010, p. 2-25, 2010.

TITTO, E.A.L. 1998. Clima: influência na produção de leite. Ambiência na produção de leite em clima quente. In: SIMPÓSIO BRASILEIRO DE AMBIÊNCIA NA PRODUÇÃO DE LEITE, 1., 1998, Piracicaba. Anais... Piracicaba: FEALQ. p.10-23, 1998.

UNITED STATES DEPARTAMENT OF AGRICULTURE. Dairy: World Markets and Trade. Dezembro, 2011. 27p.

WARREN, W.P.; MARTZ, F.A.; ASAY, K.H.; HILDERBRAND, E.S.; PAYNE, C.G.; VOGT, J.R. Digestibility and rate of passage by steers fed tall fescue, alfalfa and orchardgrass hay in 18 and $32^{\circ} \mathrm{C}$ ambient temperature. Journal of Animal Science. v.39, n.1, p.93-96, 1974.

WEST, J.W. Nutritional Strategies for managing the heat-stressed dairy cows. Journal of Animal Science, v.77, p.21-35, 1997

WEST, J.W. Effects of Heat-Stress on Production in Dairy Cattle. Journal of Dairy Science v.86, n.6, 2003

WOLFENSON, D.; FLAMENBAUM, I.; BERMAN, A. Dry period heat stress relief effects on prepartum progesterone, calf birth weight, and milk production. Journal of Dairy Science, v.71, p.809-818, 1988.

YOULSEF, M.K. Stress physiology in livestock. Boca Raton: CRC Press, 217p, 1985. 